\title{
Randomized Controlled Crossover Trial of Ketamine in Obsessive-Compulsive Disorder: Proof-of-Concept
}

\author{
Carolyn I Rodriguez*, ${ }^{, 1,2}$, Lawrence S Kegeles ${ }^{1,2}$, Amanda Levinson'2, Tianshu Feng ${ }^{1,2}$, Sue M Marcus ${ }^{1,2,3}$, \\ Donna Vermes ${ }^{1,2}$, Pamela Flood ${ }^{4}$ and Helen B Simpson ${ }^{1,2}$ \\ 'New York State Psychiatric Institute, New York, NY, USA; ${ }^{2}$ Department of Psychiatry, Columbia University, College of Physicians and Surgeons, \\ New York, NY, USA; ${ }^{3}$ Department of Biostatistics, Columbia University, Mailman School of Public Health, New York, NY, USA; ${ }^{4}$ Department of \\ Anesthesia, University of California at San Francisco, San Francisco, CA, USA
}

\begin{abstract}
Serotonin reuptake inhibitors (SRIs), the first-line pharmacological treatment for obsessive-compulsive disorder (OCD), have two limitations: incomplete symptom relief and 2-3 months lag time before clinically meaningful improvement. New medications with faster onset are needed. As converging evidence suggests a role for the glutamate system in the pathophysiology of OCD, we tested whether a single dose of ketamine, a non-competitive N-methyl-D-aspartate (NMDA) glutamate receptor antagonist, could achieve rapid antiobsessional effects. In a randomized, double-blind, placebo-controlled, crossover design, drug-free OCD adults $(n=15)$ with nearconstant obsessions received two 40-min intravenous infusions, one of saline and one of ketamine $(0.5 \mathrm{mg} / \mathrm{kg})$, spaced at least I-week apart. The OCD visual analog scale (OCD-VAS) and the Yale-Brown Obsessive-Compulsive Scale (Y-BOCS) were used to assess $O C D$ symptoms. Unexpectedly, ketamine's effects within the crossover design showed significant $(p<0.005)$ carryover effects (ie, lasting longer than I week). As a result, only the first-phase data were used in additional analyses. Specifically, those receiving ketamine $(n=8)$ reported significant improvement in obsessions (measured by OCD-VAS) during the infusion compared with subjects receiving placebo $(n=7)$. One-week post-infusion, $50 \%$ of those receiving ketamine $(n=8)$ met criteria for treatment response $(\geqslant 35 \%$ Y-BOCS reduction) vs $0 \%$ of those receiving placebo $(n=7)$. Rapid anti-OCD effects from a single intravenous dose of ketamine can persist for at least I week in some OCD patients with constant intrusive thoughts. This is the first randomized, controlled trial to demonstrate that a drug affecting glutamate neurotransmission can reduce OCD symptoms without the presence of an SRI and is consistent with a glutamatergic hypothesis of OCD.

Neuropsychopharmacology (2013) 38, 2475-2483; doi:I0.1038/npp.2013.150; published online 17 July 2013
\end{abstract}

Keywords: anxiety disorders; glutamate; OCD; ketamine; NMDA

\section{INTRODUCTION}

Serotonin reuptake inhibitors (SRIs) are the only medications approved by the Food and Drug Administration for the treatment of obsessive-compulsive disorder (OCD; Koran et al, 2007), but they often provide only limited symptom relief and typically have a 6 - to 10 -week lag time before clinically meaningful improvement (Koran et al, 2007; Lehman et al, 2004). Adding antipsychotics to SRIs helps a subset of patients (Bloch et al, 2006) but risks burdensome side effects. Identifying more effective pharmacological treatments with faster onset of action would constitute a major advance.

Abnormalities in glutamatergic function may contribute to the pathogenesis of OCD (Pittenger et al, 2011). First, studies

\footnotetext{
*Correspondence: Dr Cl Rodriguez, New York State Psychiatric Institute, I05I Riverside Drive, Unit 69, New York, NY 10032, USA, Tel: + I 212543 5637, Fax: + I 2125436515 ,

E-mail: cr2163@columbia.edu

Previous presentation: ACNP, 'Hot Topics' and Poster Presentation, 2012, Hollywood, FL, USA.

Received 6 March 20 I3; revised 8 June 20I3; accepted I0 June 20 I3; accepted article preview online 19 June 2013
}

have found significantly elevated levels of glutamate in the cerebrospinal fluid levels in treatment naïve OCD participants compared with control participants (Chakrabarty et al, 2005; Bhattacharyya et al, 2009). Second, magnetic resonance spectroscopy (MRS) studies in pediatric OCD participants found increases in glutamatergic compounds in the caudate (Rosenberg et al, 2000) and decreases in the anterior cingulate cortex (Rosenberg et al, 2004). This elevation of glutamatergic compounds the caudate normalized with successful SRI treatment (Rosenberg et al, 2000). Third, human genetic studies have associated OCD with genes that code for proteins important in glutamatergic transmission (eg, SLC1A1 (Arnold et al, 2006; Dickel et al, 2006; Shugart et al, 2009; Stewart et al, 2007; Wang et al, 2009) and GRIN2B (Arnold et al, 2004)). Fourth, MK-801, a noncompetitive antagonist of the $\mathrm{N}$-methyl-D-aspartate (NMDA)-type glutamate receptor, exacerbates OCD-like perseverative behaviors in a transgenic mouse model of OCD (McGrath et al, 2000). Moreover, directly disrupting glutamatergic transmission (ie, by deleting a postsynaptic scaffolding protein called SAPAP3; Bienvenu et al, 2008) triggered pathological OCD-like grooming behavior in mice that was reduced by SRI treatment (Welch et al, 2007). Finally, agents that modulate 
glutamate (eg, riluzole, $N$-acetylcysteine, and memantine) have been shown to ameliorate OCD symptoms in open (Aboujaoude et al, 2009; Coric et al, 2005; Feusner et al, 2009; Lafleur et al, 2006; Pittenger et al, 2011; Rodriguez et al, 2010; Stewart et al, 2010) and controlled trials (Afshar et al, 2012; Ghaleiha et al, 2013).

Ketamine is a noncompetitive antagonist of the NMDA receptor (a type of glutamate receptor). Studies in patients with unipolar and bipolar depression have found that a single intravenous infusion of ketamine can have antidepressant effects within $40 \mathrm{~min}$ of starting the infusion. These effects persist for 3-18 days, long after the drug has cleared the patient's system (Berman et al, 2000; Diazgranados et al, 2010a, b; Murrough et al, 2012; Valentine et al, 2011; Zarate et al, 2006, 2012a). We treated an unmedicated individual with OCD with ketamine $(0.5 \mathrm{mg} / \mathrm{kg}$ IV over $40 \mathrm{~min}$ ) and found rapid anti-obsessional effects that returned to baseline by 1 -week post-infusion (Rodriguez et al, 2011). Bloch et al (2012) conducted an open ketamine trial in 10 subjects with OCD and found modest but statistically significant improvement in OCD symptoms over days 1-3 following ketamine infusion compared with baseline; however, most subjects in this study were taking multiple other medications at the time of infusion.

To further investigate ketamine's effects on OCD symptoms, we conducted a randomized, controlled, double-blind, crossover study in 15 adults with OCD. We included only medication-free individuals to eliminate the possibility of drug interactions. In addition, we recruited individuals with near-constant obsessions in order to be able to attribute symptomatic change to study drug rather than external stimuli. We chose a crossover design given that the two prior studies of ketamine in OCD did not show an effect past 1 week (Rodriguez et al, 2011; Bloch et al, 2012). Crossover design allows for each subject to serve as their own control, thus reducing variability and allowing for a smaller sample size, assuming the effects of the first phase do not carryover into the second phase (Ibrahim et al, 2012).

\section{MATERIALS AND METHODS}

\section{Overview}

This study was conducted at an academic outpatient clinic. Subjects were recruited (April 2010 to November 2012) by clinical referral and advertisements. The institutional review board approved the protocol. Patients provided written informed consent.

\section{Participants}

Eligible outpatients were adults (ages 18-55) with a principal diagnosis of OCD ( $\geqslant 1$ year), who were at least moderately symptomatic (Yale-Brown Obsessive-Compulsive Scale, Y-BOCS; Goodman et al, 1989b, c; score $\geqslant 16$ ) and had near-constant intrusive obsessions ( $>8 \mathrm{~h}$ per day). Patients were required to be off all psychotropic medications including medications thought to alter brain glutamate (eg, memantine, riluzole). Patients on average were off all psychotropic medications for 2.9 years $(S D=2.1$ years, range 8 months to 6.5 years). Patients had failed at least one prior trial of SRI and/or cognitive behavior therapy with exposure and response prevention (EX/RP) or refused these treatments for individual reasons.

Depressive and anxiety axis I diagnoses were permitted if the OCD symptoms were the most severe and impairing. However, patients were excluded for a Hamilton Depression Rating Scale (HDRS-17) score $\geqslant 25$ (Hamilton, 1960). Patients were also excluded for bipolar, psychotic, or eating disorders, substance dependence (including nicotine), substance abuse within the past year, or prominent suicidal ideation. Patients with first-degree relative with schizophrenia were also excluded. In addition, patients were excluded if they had an unstable medical or neurological condition that increased the risk of participation (eg, dementia), if they were pregnant or nursing, or if they had started EX/RP within 8 weeks of enrollment.

Trained clinicians determined eligibility during a clinical interview; diagnoses were confirmed by trained raters using the Structured Clinical Interview for DSM-IV (First et al, 1996). Treatment history was confirmed with the referring clinician, chart review, and/or pharmacy records.

\section{Infusion Procedures}

Participants $(n=15)$ received two intravenous infusions, one of saline and one of ketamine $(0.5 \mathrm{mg} / \mathrm{kg})$, each over $40 \mathrm{~min}$. These infusions were administered at least 1 -week apart; the order of each infusion pair was randomized. Blood ketamine levels were collected to confirm infusion type. Continuous vital signs during the infusion were monitored with EKG monitor, blood oxygen saturation, and blood pressure cuff.

\section{Assessments}

To assess rapid changes in obsessions during and after the infusion, patients self-rated severity of obsessions using the OCD-VAS (Rodriguez et al, 2011), a modified self-rating scale used previously to detect acute changes in OCD symptoms (Abrantes et al, 2009; Greenberg et al, 1998; Murphy et al, 1989), at baseline, during the infusion, at 90, 110,230 -min post-infusion, and daily for 1-week postinfusion. We focused on obsessions because the patients were supine and connected to stationary monitoring equipment during the infusion; thus, compulsions requiring ambulation were constrained. In addition, an independent evaluator (IE), blind to treatment, evaluated patients at baseline and one week after each infusion using the Y-BOCS, which appraises obsessive and compulsive symptoms over the prior week. Treatment response was defined a priori as least a $35 \% \mathrm{Y}-\mathrm{BOCS}$ reduction in OCD severity (Tolin et al, 2005). The HDRS-17 (Hamilton, 1960) was used to evaluate depression severity at baseline and 1 and 3 days post-infusion.

A study psychiatrist, who was blind to randomization, assessed degree of dissociation (measured by the ClinicianAdministered Dissociative States Scale (CADSS) at baseline, mid-infusion, $110 \mathrm{~min}, 230 \mathrm{~min}$, and 7 days; Bremner et al, 1998); manic symptoms (on 11-item Young Mania Rating Scale (YMRS) at baseline, $230 \mathrm{~min}$, and 7 days; Young et al, 1978); and psychotic symptoms (on the Brief Psychiatric Rating Scale (BPRS) at baseline, mid-infusion, $110 \mathrm{~min}$, $230 \mathrm{~min}$, and 7 days; Overall and Gorham, 1962). At 90, 110, 
and 230-min post-infusion, the study psychiatrist systematically inquired about other possible side effects (ie, dizziness) and elicited the patient's qualitative experience.

\section{Statistical Analyses}

SAS software was used to conduct mixed-effects linear regression of each continuous outcome (OCD-VAS, HDRS-17) as a function of infusion type $(=1$ for ketamine, $=0$ for placebo), infusion order ( $=1$ for ketamine first, $=0$ for placebo first), time, and all interactions. Mixed-effects regression accounts for the clustering of repeated measures within subjects and can incorporate data from subjects who may have one or more missing observations as mixedeffects models using maximum likelihood estimation provide valid inferences in the presence of ignorable nonresponse (Papolos et al, 2012). First, we looked for evidence of a carryover effect (ie, whether the effect of order or any order-by-infusion-type interactions were significant) using the OCD-VAS and Y-BOCS to confirm that the data could be collapsed across phases. In the presence of a significant carryover effect, we planned to analyze the first phase only using the model described above without the order main effect and interaction terms.

To examine OCD symptom severity, the OCD-VAS was analyzed in a piece-wise linear manner: from baseline to mid-infusion, mid-infusion to 230 -min post-infusion, and days 1-7 post-infusion. Our analyses assessed differences between ketamine and placebo using contrasts within each mixed-effects linear regression model (Gibbons et al, 1993). The same model was used to examine depression severity (at baseline, day 1 , and day 3 post-infusion) with the HDRS-17. Effect sizes were calculated using the estimates divided by the baseline SD for each outcome. In addition, we looked at a binary treatment response, defined as greater than or equal to a $35 \%$ decrease in Y-BOCS score between baseline and 1-week post-infusion. Proportions of individuals meeting criteria for treatment response were compared for ketamine $v s$ placebo status using a $\chi^{2}$ test. All tests were two-sided with a significance level of $p=0.05$.

Finally, we explored the relationship between ketamine, norketamine, and dehydronorketamine blood levels and OCD outcomes as well as the severity of dissociative, psychotic, and manic symptoms (for OCD-VAS, mixedeffect linear regression as a function of blood level, time, and all interactions; for responders $v s$ nonresponders, independent samples $t$-test; for CADSS, BPRS, YMRS, and Pearson correlation).

\section{RESULTS}

\section{Sample}

Of the 31 subjects screened, 16 were excluded for not meeting the inclusion/exclusion criteria (Figure 1). Fifteen subjects met entry criteria and were randomized to receive one infusion of ketamine and one infusion of saline.

Table 1 presents patient demographic and clinical characteristics. The sample was $56 \%$ male, $44 \%$ female, 44\% African American, 27\% Caucasian, 19\% Hispanic, and $7 \%$ Asian. The mean age of the sample was 34.2 years $(\mathrm{SD}=9.0$ years $)$. Patients had severe OCD symptoms: mean
Y-BOCS score at baseline was $28.2(\mathrm{SD}=3.9)$, with mean illness duration of 18.2 years $(\mathrm{SD}=10.4$ years $)$. Two subjects (13\%) met criteria for comorbid major depression; both had mild-to-moderate depression (HDRS-17 scores were 13 and 16). The mean number of prior adequate SRI trials was $1.6(\mathrm{SD}=2.1), 13 \%$ failed at least one prior adequate trial of antipsychotic augmentation, and $47 \%$ failed at least one prior adequate trail of EX/RP. Data from community (Blanco et al, 2006), managed care (Koran et al, 2000), and university-based clinics (Eisen et al, 1999) show a range of $40-68 \%$ of OCD patients received at least one prior adequate trial of an SRI. In our sample, 53\% received at least one adequate trial of an SRI. Subjects' obsessions covered a wide spectrum of symptom dimensions, with cleaning/contamination as the predominant type (Table 1). Comparison of the demographics of the two groups randomized to different infusion order showed no statistical differences between sex, age, race, or number of prior SRI trials.

\section{Test of Carryover Effects}

Patients were randomized to one of two orders of infusions (Figure 1): arm A (ketamine first and saline second) or arm B (saline first and ketamine second). In Figure 2, OCD-VAS for each of these four infusions (ketamine first, saline first, ketamine second, and saline second) from baseline to 1 -week post-infusion is plotted. On average, patients receiving ketamine first did not return to their baseline OCD-VAS score before the saline second infusion $(p<0.05)$, indicative of a significant carryover effect. Specifically, the mean estimated baseline OCD-VAS score in those receiving saline second was significantly lower (by -3.3 points, SE $1.1, p<0.005)$ than the mean baseline of the other three infusions (ie, saline first, ketamine first, and ketamine second; Figure 2). We also found a significant carryover effect on the Y-BOCS, as shown by a significant mean estimated reduction (by -10.8 points, SE $3.5, p<0.01$ ) in baseline Y-BOCS score in those receiving saline second infusion than the mean baseline of the other three infusions (ie, ketamine first, saline first, and ketamine second). These carryover effects indicate that the reduction in obsessional symptoms (as measured by the OCD-VAS) and in overall OCD symptoms (as measured by the Y-BOCS) following ketamine infusion persisted beyond the expected 1 week. As a result of the carryover effects, data from both phases could not be collapsed.

\section{First-Phase Analysis}

To examine data independent of carryover effects, only the first-phase data (ketamine first $(n=8)$, saline first $(n=7)$ ) were used in additional analyses, as proposed in the statistical methods. Obsessive severity as measured by OCD-VAS significantly differed at mid-infusion, 230-min post-infusion and 7 days post-infusion between those that received ketamine and those that received saline. Specifically, those receiving ketamine had lower mean estimated baseline OCD-VAS score at mid-infusion (by -4.52 points, $\mathrm{SE}=1.23, p<0.005$ ), $230 \mathrm{~min}$ (by 3.84 points, $\mathrm{SE}=1.59$, $p<0.05$ ), and 7 days (by -3.67 points, $\mathrm{SE}=1.36, p<0.05$ ) post infusion, each with large effect size (Cohen's $d>0.8$ ), 


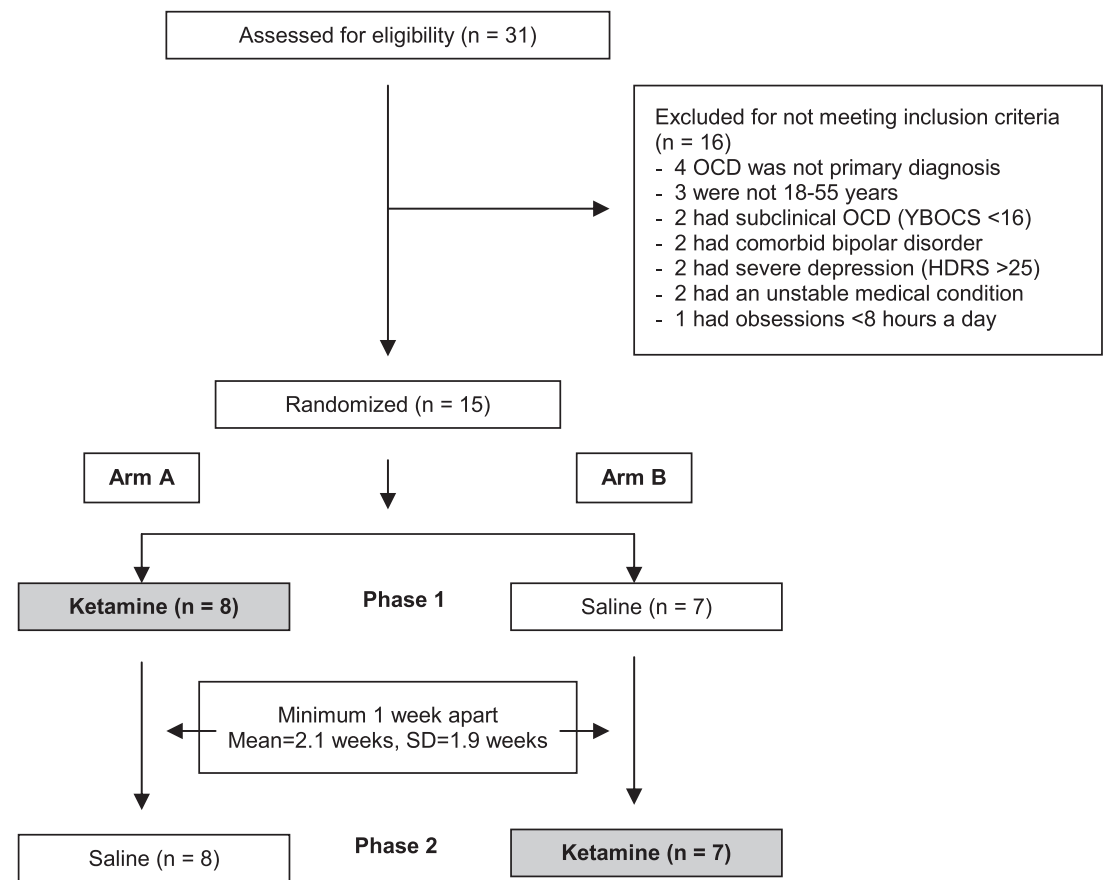

Figure I Consort diagram showing flow of patients through the study. Enrollment, randomization, and completion of two treatment phases ( $n=\mid 5$ ).

Table I Demographic, Clinical, and Outcome Data of OCD Participants

\begin{tabular}{|c|c|c|c|c|c|c|c|c|c|c|c|}
\hline $\begin{array}{l}\text { Age/sex/ } \\
\text { ethnicity }\end{array}$ & $\begin{array}{l}\text { Age of } \\
\text { OCD } \\
\text { onset }\end{array}$ & $\begin{array}{l}\text { Duration } \\
\text { of illness }\end{array}$ & $\begin{array}{l}\text { Comorbid } \\
\text { diagnoses }\end{array}$ & $\begin{array}{l}\text { Prior } \\
\text { EX/RP } \\
\text { trials }\end{array}$ & $\begin{array}{l}\text { Prior } \\
\text { SRI } \\
\text { trials }\end{array}$ & $\begin{array}{l}\text { Treatment } \\
\text { order }\end{array}$ & $\begin{array}{l}\text { Y-BOCS } \\
\text { pre/post } \\
\text { ketamine }\end{array}$ & $\begin{array}{l}\text { Y-BOCS } \\
\text { pre/post } \\
\text { saline }\end{array}$ & $\begin{array}{l}\text { HDRS-I } 7 \\
\text { pre/post } \\
\text { ketamine }\end{array}$ & $\begin{array}{l}\text { HDRS-I } 7 \\
\text { pre/post } \\
\text { saline }\end{array}$ & $\begin{array}{l}\text { Baseline OCD } \\
\text { symptom } \\
\text { domain }\end{array}$ \\
\hline $24 / \mathrm{M} / \mathrm{H}$ & 19 & 5 & None & No & 0 & $P$ & $24 / 27$ & $22 / 24$ & $4 / 3$ & $4 / 2$ & $\mathrm{Cln}$ \\
\hline 47/M/AA & 28 & 19 & MDD & Yes & 3 & K & $26 / 14^{a}$ & $21 / 25$ & $16 / 6$ & $4 / 5$ & $\begin{array}{l}\text { Cln, Sym, Hrd, } \\
\text { Dbt, Tab }\end{array}$ \\
\hline $32 / \mathrm{M} / \mathrm{H}$ & 18 & 14 & None & No & 0 & K & $20 / 22$ & $22 / 18$ & $2 / 2$ & $4 / 4$ & Cln, Sym \\
\hline $27 / F / C$ & 14 & 13 & None & No & 0 & $P$ & $25 / 15$ & $25 / 25$ & $2 / 2$ & $6 / 2$ & $\begin{array}{l}\text { Cln, Sym, Hrd, } \\
\text { Dbt, Tab }\end{array}$ \\
\hline 53/M/C & 38 & 15 & None & No & I & K & $29 / 12^{a}$ & $12 / 10$ & $0 / 0$ & $0 / 0$ & Cln, Sym, Tab \\
\hline 38/F/A & 16 & 22 & None & No & 2 & $P$ & $36 / 31$ & $37 / 36$ & $2 / 1$ & $1 / \mid$ & Cln, Sym \\
\hline 45/M/C & 6 & 39 & None & Yes & 7 & $P$ & $20 / 15^{b}$ & $30 / 20$ & $4 / 6$ & $3 / 0$ & $\begin{array}{l}\text { Cln, Sym, Hrd, } \\
\text { Dbt, Tab }\end{array}$ \\
\hline 29/F/AA & 5 & 24 & None & Yes & I & K & $28 / 24$ & $27 / 27$ & $6 / 1$ & $2 / 3$ & Cln, Sym, Dbt \\
\hline $32 / M / C$ & 21 & 11 & None & Yes & 3 & $P$ & $12 / 19$ & $23 / 16$ & $4 / 1$ & $2 / 1$ & Dbt, Tab \\
\hline 29/F/AA & 15 & 14 & None & No & 4 & K & 29/30 & $3|/ 3|$ & $5 / 8$ & ||$/||$ & Dbt, Hrd \\
\hline
\end{tabular}

Abbreviations: A, Asian; AA, African American; C, Caucasian; EX/RP, cognitive behavior therapy with exposure and response prevention; F, female; H, Hispanic; HDRS, Hamilton Depression Rating Scale; M, male; MDD, major depressive disorder; OCD, obsessive-compulsive disorder; SAD, social anxiety disorder; SP, specific phobia; SRI, serotonin reuptake inhibitor; Y-BOCS, Yale-Brown Obsessive-Compulsive Scale.

Symptom dimensions were based on a five-factor model (Pinto et al, 2008; Schooler et al, 2008) and listed in order of clinical severity for each subject: Cln (contamination/cleaning); Dbt (doubt/checking); Hrd (hoarding); Sym (symmetry/ordering); Tab (taboo thoughts (aggressive, sexual, and religious obsessions)).

Y-BOCS was rated at baseline before infusion (pre) and I-week post-infusion (post).

Treatment order- K: ketamine first and placebo second; P: placebo first and ketamine second.

${ }^{a} \geqslant 35 \%$ reduction in Y-BOCS rating scale (ie, treatment responders to ketamine in first phase).

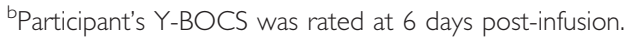




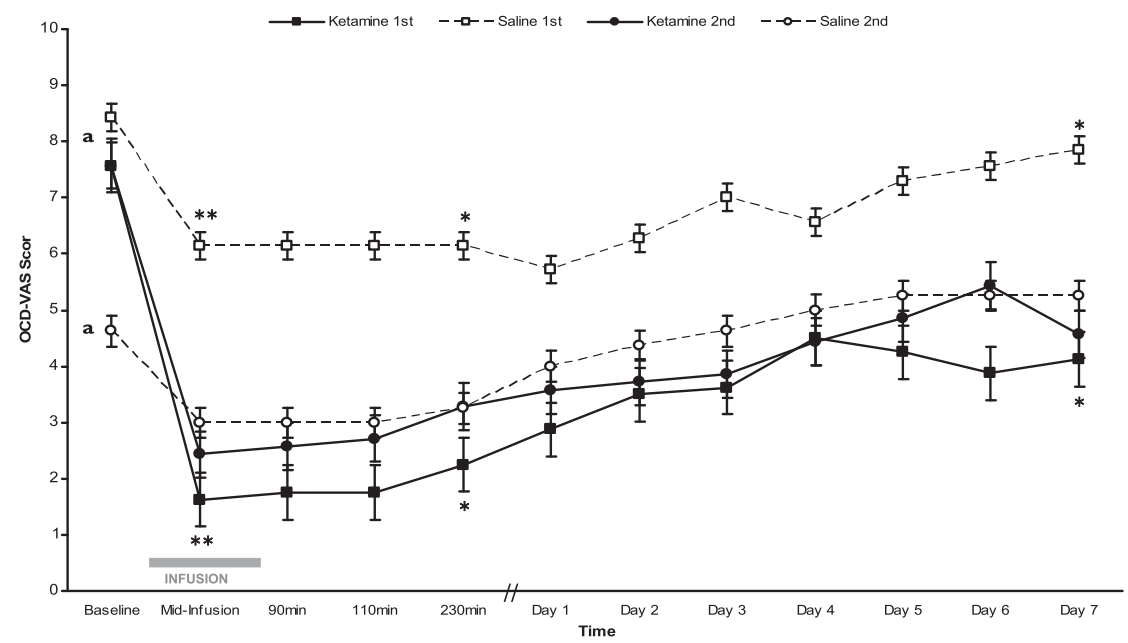

Figure 2 Change in obsessions over I-week post-infusion type (ketamine or saline) by order of administration (first or second). Obsessions measured by the OCD-VAS scores for each infusion type (ketamine or saline) by order of administration (first or second) over I week. An OCD-VAS score of IO represents constant, intrusive obsessions and 0 represents no obsessions. Dark lines represent patients given ketamine and dashed lines represent patients given saline. Square boxes depict phase I (filled square is ketamine first and open square is saline first) and circles depict phase 2 (filled circle is ketamine second and open circle is saline second). Error bars indicate SE. ${ }^{a}$ Carryover effects of ketamine were assessed by comparing the baseline score of saline second with mean baseline of the other three groups (saline first, ketamine first, and ketamine second); these carryover effects were significant (see 'Test of Carryover Effects' section). To examine data independent of carryover effect, only phase I data were analyzed: ketamine first (filled square) was compared with saline first (open square) at mid-infusion, $230 \mathrm{~min}$, and day 7 post-infusion. ${ }^{*} p<0.05$; ${ }^{*} * 0<0.005$.

than those receiving placebo (Figure 2). In addition, a significantly higher proportion of those receiving ketamine $(n=8)$, met criteria for treatment response $(\geqslant 35 \%$ reduction in Y-BOCS score) compared with those receiving placebo $\left(50 \%\right.$ vs $\left.0 \% ; X^{2}(1, N=15)=4.77, p<0.05\right)$.

Depression severity as measured by the HDRS-17 did not significantly differ at baseline or 3 days post-infusion between those that received ketamine and those that received saline. Specifically, those receiving ketamine had a mean estimated difference in HDRS-17 score at baseline higher (by 1.37 points, $\mathrm{SE}=1.67, p=0.42$ ) and 3 days postinfusion lower (by $-1.17, \mathrm{SE}=1.86, p=0.53$ ) than those receiving placebo.

\section{Description of Ketamine's Effect in Individuals Randomized to Saline First}

As described above, statistical analyses for the second phase are not easily interpretable because of carryover effects of ketamine. As shown visually in Figure 2, individuals who received ketamine first and those who received ketamine second had a similar reduction in OCD-VAS with no significant differences (OCD VAS mean estimated difference (SE): baseline $=0.18$ points $(1.34), p=0.89$; mid-infusion $=$ -0.59 (1.43), $p=0.68$; and day $7=-1.46$ (1.54), $p=0.35$ ). One week after ketamine infusion, one of seven met criteria for treatment response ( $\geqslant 35 \%$ decrease in Y-BOCS).

\section{Side Effects}

Consistent with prior studies using sub-anesthetic doses of IV ketamine, all participants $(n=15)$ experienced mild elevations in blood pressure and pulse during the ketamine infusion and stable blood and pulse during saline infusion. Figure 3 illustrates the rates of dissociation, positive psychotic symptoms, and manic symptoms in all
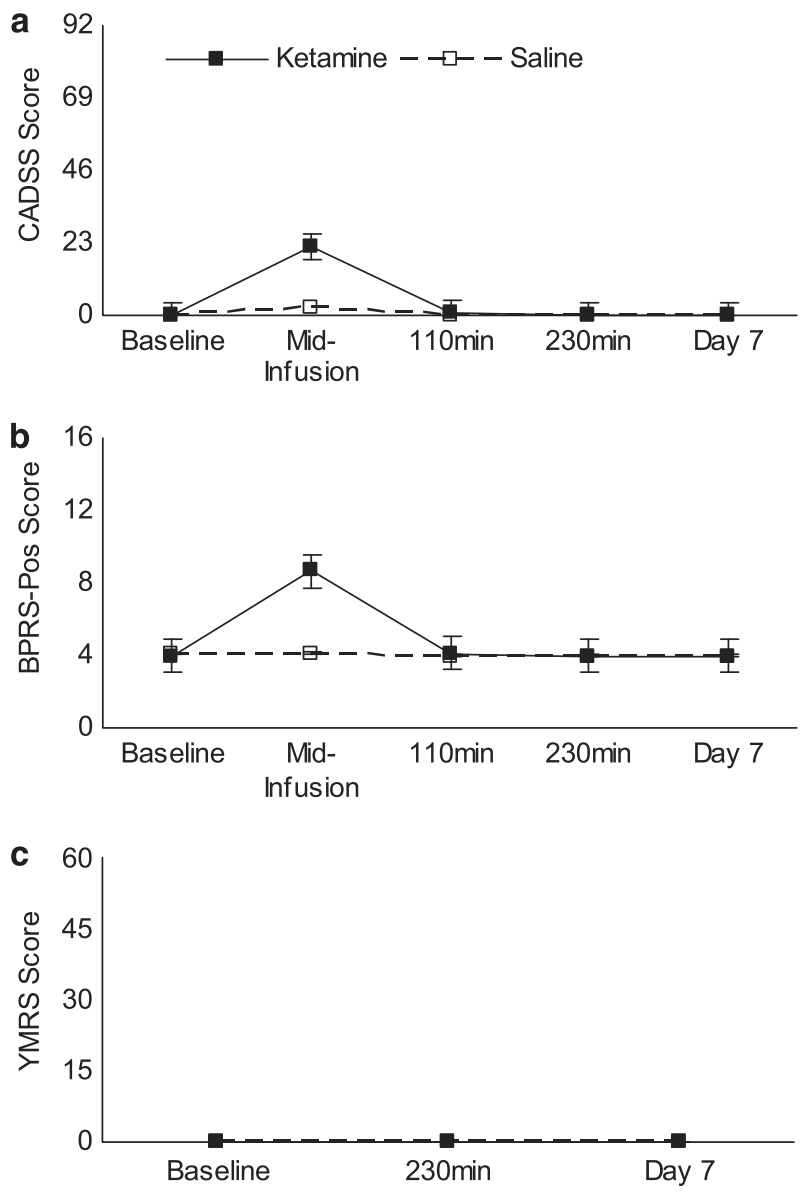

Figure 3 Side effects for phases 1 and 2 combined. Change in sideeffects of (a) dissociation, CADSS, (b) positive psychotic symptoms, BPRS, and (c) mania, YMRS. Dark lines represent patients given ketamine $(n=15)$ and dashed lines represent patients given saline $(n=15)$. Each figure displays mean scores for each scale over time. 
participants $(n=15)$. The most commonly reported symptoms that occurred during the ketamine infusion were symptoms of dissociation (ie, feelings of unreality $(n=14)$ and distortions of time $([n=13))$, positive psychotic symptoms (ie, unusual thought content $(n=12)$, conceptual disorganization $(n=10)$ ), and manic symptoms (ie, elevated $\operatorname{mood}(n=1))$.

At post-infusion, participants reported dizziness $(n=3)$, nausea $(n=2)$, vomiting $(n=1)$, and headache $(n=2)$, which resolved within $110 \mathrm{~min}$ of the start of infusion; none were reported during the saline infusion. In the week postketamine infusion, participants did not report side effects; in the week post-saline infusion, one participant reported constipation at day 2 and day 3 post-infusion. No serious adverse events occurred during the study.

\section{Ketamine Blood Levels}

After ketamine infusion, all subjects $(n=15)$ had detectable ketamine and ketamine metabolite blood levels $(\mathrm{ng} / \mathrm{ml})$ at $90 \mathrm{~min} \quad$ (ketamine $=79.9 \pm 27.1$; norketamine $=45.3 \pm 15.6$; dehydronorketamine $=25.1 \pm 8.6)$ and $120 \mathrm{~min}$ (ketamine $=$ $63.1 \pm 21.9$; norketamine $=51.3 \pm 16.4$; dehydronorketamine $=28.6 \pm 11.8$ ). After saline infusion, no subjects had detectable ketamine, norketamine, or dehydronorketamine blood levels at 90 or $120 \mathrm{~min}$. There were no significant associations between ketamine, norketamine, or dehydronorketamine blood levels and OCD-VAS scores at any time points (all p's $>0.05)$. Responders ( $>35 \%$ decrease in Y-BOCS) and non-responders did not significantly differ in ketamine, norketamine, or dehydronorketamine blood levels at 1-week post-infusion (all p's $>0.05$ ). No significant correlation was found between ketamine, norketamine, and dehydronorketamine blood levels and levels of dissociation, positive psychotic symptoms, or mania, as measured by the CADSS, BPRS, and YMRS (all p's >0.05).

\section{DISCUSSION}

We conducted a randomized, controlled study of the effects of ketamine, a non-competitive NMDA glutamate receptor antagonist, in adults with OCD. There were three main findings. (1) Participants receiving ketamine first showed significant rapid reduction in obsessions during the infusion that persisted until 1-week post-infusion compared with participants receiving placebo first. (2) Half of participants receiving ketamine first met treatment response criteria at 1-week post-infusion. (3) There were significant carryover effects suggesting that ketamine's effects on OCD symptoms last longer than previously reported. This is the first randomized, controlled trial to demonstrate that a drug affecting glutamate neurotransmission can reduce OCD symptoms without the presence of an SRI and is consistent with a glutamatergic hypothesis of OCD.

That ketamine had rapid anti-obsessional effects compared with placebo is consistent with our prior case report, in which a patient with constant intrusive obsessions reported rapid anti-obsessional effects with a single dose of ketamine that lasted from mid-infusion up to 3 days post-infusion (Rodriguez et al, 2011). Our findings contrast with those of the Bloch et al (2012) open trial, which found only modest reductions in OCD symptoms 1-3 days postketamine infusion, and no subjects who met response criteria ( $\geqslant 35 \%$ Y-BOCS reduction) after 1 week.

Sampling and methodological differences may explain the discrepancy in findings between our study and those of the Bloch et al (2012) study. First, we included only subjects with nearly constant intrusive obsessions ( $>8 \mathrm{~h}$ a day), whereas Bloch et al (2012) did not require their subjects to have constant obsessions. Individuals with constant intrusive obsessions may represent an OCD subtype more sensitive to ketamine's effects. Alternatively, measuring the anti-obsessional effects of ketamine may be difficult in individuals whose obsessions are not reliably constant. Second, our study required subjects to be medication free, whereas Bloch et al (2012) allowed concomitant medications (7 of 10 took SRIs; 4 of 10 took antipsychotics; 3 of 10 took benzodiazepines; 1 of 10 took glutamate modulators (riluzole and $\mathrm{N}$-acetylcysteine)). Concomitant medications might influence ketamine's clinical OCD effects. Third, subjects in our study had an average dissociation level of 22 on the CADSS by mid-infusion and returned to baseline by $110 \mathrm{~min}$, whereas Bloch et al's subjects reported an average dissociation of 1.4 on the CADSS rating in the hour of infusion. Level of dissociation may influence ketamine's effects in OCD. Fourth, in our study 2 of 15 subjects had comorbid depression (with baseline HDRS-17 scores of 13 and 16), and no significant differences in depression between infusion type. In contrast, in Bloch et al's trial, 7 out of 10 subjects had comorbid depression (individual HDRS-17 scores not reported), and the percentage reduction in depressive symptoms in the first 3 days after ketamine infusion were significantly greater than the reduction in OCD symptoms. Perhaps OCD patients with comorbid depression represent a subtype of illness that is ironically less responsive to ketamine effects on OCD symptoms.

That there were significant carryover effects was unexpected, given that two prior reports find that ketamine's effects on OCD symptoms did not persist past 1 week (Bloch et al, 2012; Rodriguez et al, 2011). The benefits and drawbacks of crossover designs have been previously reviewed (Ibrahim et al, 2012). Future studies of ketamine's effects in OCD that use a crossover design should allow for greater time period between infusions than we did to enable return to baseline, or they should use a parallel design.

The OCD-VAS scores between individuals who received ketamine first $v s$ those who received ketamine second did not differ at any time-point out to 7 days post-infusion. On the other hand, the response rate on the Y-BOCS 1 week after the infusion was different in phase 1 (50\%) and phase $2(11 \%)$. Small sample size in each group may explain this variability. A contributing factor may be limitations in the Y-BOCS to detect rapid changes, since the Y-BOCS measures symptoms averaged over the past week. We cannot exclude differential expectancy effects. Future studies should use a larger sample size, detailed assessment of expectancy effects with respect to blinding, and/or an active control.

The rapid anti-obsessional effects of ketamine contrast with those of memantine, an orally administered, noncompetitive NMDA antagonist with lower affinity than ketamine. Memantine has been demonstrated to be an 
effective augmentation strategy in SRIs in both open label (Aboujaoude et al, 2009; Stewart et al, 2010; Feusner et al, 2009) and a randomized controlled trial (Ghaleiha et al, 2013); however, memantine had a lag time of 8-12 weeks for full clinical benefits in these studies. Two differences might explain the difference in time to clinical effect observed with memantine $v s$ ketamine in the present trial. First, memantine was tested as an augmentation to SRIs whereas individuals were drug free in the current ketamine study. As mentioned earlier, concomitant medications might affect the clinical impact of NMDA channel blockers such as memantine and ketamine. Second, relative to memantine, ketamine has higher affinity for the NMDA receptor, different effects on channel gating, and different binding sites within the open channel (Johnson and Kotermanski, 2006). These may account for its rapid effects.

Three limitations deserve consideration. First, this proof of concept trial has a small sample size. Replication is needed. Second, patient blinding was difficult because of the psychoactive effects of ketamine, and thus self-rating forms may be subject to bias. In our study, a physician rated side effects and vital signs separately from the IE, who evaluated only clinical symptoms (eg, Y-BOCS) to protect the blind as much as possible. Future study designs should consider use of an active comparator that produces psychogenic effects. Third, although ketamine binds to the NMDA receptor with an affinity several-fold higher than at other sites (Johnson and Kotermanski, 2006), interactions with other receptors cannot be excluded.

Our findings suggest important directions for future research. First, we need to understand ketamine's mechanism of action. Microdialysis studies in rats suggest that ketamine acutely increases release of a surge of glutamate in the prefrontal cortex (Moghaddam et al, 1997). MRS of the effects of ketamine in the prefrontal cortex and other brain regions have been assessed (Rowland et al, 2005; Stone et al, 2012; Taylor et al, 2012; Valentine et al, 2011) and in some cases (but not all) a ketamine-induced increase in glutamatergic compounds has been reported. However, a glutamate surge is transient and cannot account for persistent anti-depressant and anti-OCD effects. Hence, further research exploring downstream mechanisms such as reported changes in synaptogenesis via mammalian target of rapamycin (Li et al, 2010), enhanced synaptic efficacy via inhibition of eukaryotic elongation factor (eEF2) kinase, dephophorylation of eEF2, and augmentation of BDNF synthesis (Monteggia et al, 2012) is needed. Second, alternate ways of modulating the NMDA receptor complex to produce symptom reduction without psychotomimetic effects are needed. Recent research studies have explored two avenues: one method is to utilize compounds with a lower binding affinity to the receptor complex, (eg, using AZD6765, a low-trapping NMDA channel blocker; Zarate et $\mathrm{al}, 2012 \mathrm{~b}$ ) and another method is to target specific NMDA receptor subunits (eg, using MK-0657 to target the NR2B subunit; Ibrahim et al, 2012). Both AZD6765 and MK-0657 compounds were recently shown to produce anti-depressant effects without psychotomimetic effects (Ibrahim et al, 2012; Zarate et al, 2012b). Third, ketamine has demonstrated affinity for other receptors; characterizing its effect on the specificity at NMDA $v s$ other receptors is needed. Fourth, other ways to rapidly assess impact of ketamine on compulsions are needed. In the present study, a visual analog scale (VAS; ranging from 0 to 10) was used to measure rapid changes in OCD symptoms. In the Bloch et al (2012) open-label study, two Y-BOCS items that usually measure time occupied by obsessions and compulsions were modified to measure the frequency of these events instead. Another option is the Yale-Brown ObsessiveCompulsive Challenge Scale (Y-BOCCS), a visual analog scale that was adapted from the Y-BOCS for testing at shortintervals (Goodman et al, 1989a), which characterizes obsessions and compulsions in multiple domains (eg, duration, frequency, and intensity) may provide greater insight into how ketamine impacts all OCD symptoms.

It is worth noting that participants in the study who met response criteria $(n=4)$ after ketamine infusion described their experience as overall positive, despite reports of psychotomimetic side effects: (1)'I feel as if the weight of OCD has been lifted... I want to feel this way forever;' (2) 'I feel like someone is giving me an explanation [for my OCD];' (3) 'I don't have any intrusive thoughts. I was laughing when you couldn't find the key, which normally is a trigger for me. This is amazing, unbelievable. This is right out of a movie;' (4) 'I tried to have OCD thoughts, but I couldn't.' There could be potentially a place for the use of ketamine for OCD patients who do not respond to first-line treatments for OCD.

In summary, this study indicates that ketamine can have rapid anti-obsessional effects, and these effects can persist for at least 1 week in some patients with OCD. Future research must clarify the mechanism of ketamine's acute effects and why some (but not all) patients benefit. Ketamine may provide a useful tool to study the glutamatergic mechanism implicated in OCD and, if proven effective, may help identify novel drug targets for this disabling illness.

\section{FUNDING AND DISCLOSURE}

Dr Carolyn I Rodriguez, Amanda Levinson, Tianshu Feng, Donna Vermes, and Dr Sue M Marcus report no financial relationships with commercial interests. Dr Lawrence $S$. Kegeles has received research funds from Amgen and Pfizer. Dr Pamela Flood reports an equity interest in Signature Pharmaceuticals. Dr Helen Blair Simpson has received research funds from Janssen Pharmaceuticals (2006-2012) and Transcept Pharmaceuticals (2011-2013), royalties from Cambridge University Press and UpToDate, and consultated for Quintiles (September 2012).

\section{ACKNOWLEDGEMENTS}

We thank the individuals suffering from OCD who generously donated their time to participate in this research study. We also thank Dr John Markowitz, for his feedback on the manuscript. This investigation was supported by grants from National Institutes of Mental Health K23MH092434 (Dr Rodriguez), K24MH09155 (Dr Simpson), Gray Matters Fellowship (Dr Rodriguez), Pisetsky Young Investigator Award (Dr Rodriguez), Molberger Scholar Award (Dr Rodriguez), NCRR/NIH CTSA UL1 RR024156, and the New York State Psychiatric Institute (Donna Vermes and Drs Kegeles and Simpson). 


\section{REFERENCES}

Aboujaoude E, Barry JJ, Gamel N (2009). Memantine augmentation in treatment-resistant obsessive-compulsive disorder: an openlabel trial. J Clin Psychopharmacol 29: 51-55.

Abrantes AM, Strong DR, Cohn A, Cameron AY, Greenberg BD, Mancebo MC et al (2009). Acute changes in obsessions and compulsions following moderate-intensity aerobic exercise among patients with obsessive-compulsive disorder. J Anxiety Disord 23: 923-927.

Afshar H, Roohafza H, Mohammad-Beigi H, Haghighi M, Jahangard L, Shokouh P et al (2012). N-acetylcysteine add-on treatment in refractory obsessive-compulsive disorder: a randomized, double-blind, placebo-controlled trial. J Clin Psychopharmacol 32: 797-803.

Arnold PD, Rosenberg DR, Mundo E, Tharmalingam S, Kennedy JL, Richter MA (2004). Association of a glutamate (NMDA) subunit receptor gene (GRIN2B) with obsessive-compulsive disorder: a preliminary study. Psychopharmacology (Berl) 174: 530-538.

Arnold PD, Sicard T, Burroughs E, Richter MA, Kennedy JL (2006). Glutamate transporter gene SLC1A1 associated with obsessivecompulsive disorder. Arch Gen Psychiatry 63: 769-776.

Berman RM, Cappiello A, Anand A, Oren DA, Heninger GR, Charney DS et al (2000). Antidepressant effects of ketamine in depressed patients. Biol Psychiatry 47: 351-354.

Bhattacharyya S, Khanna S, Chakrabarty K, Mahadevan A, Christopher R, Shankar SK (2009). Anti-brain autoantibodies and altered excitatory neurotransmitters in obsessive-compulsive disorder. Neuropsychopharmacology 34: 2489-2496.

Bienvenu OJ, Wang Y, Shugart YY, Welch JM, Grados MA, Fyer AJ et al (2008). Sapap3 and pathological grooming in humans: results from the OCD collaborative genetics study. Am J Med Genet B Neuropsychiatr Genet 150B: 710-720.

Blanco C, Olfson M, Stein DJ, Simpson HB, Gameroff MJ, Narrow WH (2006). Treatment of obsessive-compulsive disorder by U.S. psychiatrists. J Clin Psychiatry 67: 946-951.

Bloch MH, Landeros-Weisenberger A, Kelmendi B, Coric V, Bracken MB, Leckman JF (2006). A systematic review: antipsychotic augmentation with treatment refractory obsessivecompulsive disorder. Mol Psychiatry 11: 622-632.

Bloch MH, Wasylink S, Landeros-Weisenberger A, Panza KE, Billingslea E, Leckman JF et al (2012). Effects of ketamine in treatment-refractory obsessive-compulsive disorder. Biol Psychiatry 72: 964-970.

Bremner JD, Krystal JH, Putnam FW, Southwick SM, Marmar C, D.S. C (1998). Measurement of dissociative states with the Clinician-Administered Dissociative States Scale (CADSS). J Trauma Stress 11: 125-136.

Chakrabarty K, Bhattacharyya S, Christopher R, Khanna S (2005). Glutamatergic dysfunction in OCD. Neuropsychopharmacology 30: $1735-1740$.

Coric V, Taskiran S, Pittenger C, Wasylink S, Mathalon DH, Valentine $G$ et al (2005). Riluzole augmentation in treatmentresistant obsessive-compulsive disorder: an open-label trial. Biol Psychiatry 58: 424-428.

Diazgranados N, Ibrahim L, Brutsche NE, Newberg A, Kronstein P, Khalife $S$ et al (2010a). A randomized add-on trial of an $\mathrm{N}$-methyl-D-aspartate antagonist in treatment-resistant bipolar depression. Arch Gen Psychiatry 67: 793-802.

DiazGranados N, Ibrahim LA, Brutsche NE, Ameli R, Henter ID, Luckenbaugh DA et al (2010b). Rapid resolution of suicidal ideation after a single infusion of an N-methyl-D-aspartate antagonist in patients with treatment-resistant major depressive disorder. J Clin Psychiatry 71: 1605-1611.

Dickel DE, Veenstra-VanderWeele J, Cox NJ, Wu X, Fischer DJ, Van Etten-Lee $M$ et al (2006). Association testing of the positional and functional candidate gene SLC1A1/EAAC1 in early-onset obsessive-compulsive disorder. Arch Gen Psychiatry 63: 778-785.

Eisen JL, Goodman WK, Keller MB, Warshaw MG, DeMarco LM, Luce DD et al (1999). Patterns of remission and relapse in obsessive-compulsive disorder: a 2-year prospective study. J Clin Psychiatry 60: 346-351.

Feusner JD, Kerwin L, Saxena S, Bystritsky A (2009). Differential efficacy of memantine for obsessive-compulsive disorder vs generalized anxiety disorder: an open-label trial. Psychopharmacol Bull 42: 81-93.

First MB, Spitzer RL, Gibbon M, Williams JB (1996). Structured Clinical Interview for DSM-IV Axis I Disorders-Patient Edition. Biometrics Research Department, New York State Psychiatric Institute: New York, NY, USA.

Ghaleiha A, Entezari N, Modabbernia A, Najand B, Askari N, Tabrizi M et al (2013). Memantine add-on in moderate to severe obsessive-compulsive disorder: randomized double-blind placebo-controlled study. J Psychiatr Res 47: 175-180.

Gibbons RD, Hedeker D, Elkin I, Waternaux C, Kraemer HC, Greenhouse JB et al (1993). Some conceptual and statistical issues in analysis of longitudinal psychiatric data. Application to the NIMH treatment of Depression Collaborative Research Program dataset. Arch Gen Psychiatry 50: 739-750.

Goodman W, Price LH, Woods SW, Charney DS (1989a). Pharmacologic challenges in obsessive-compulsive disorder. Psychobiology of OCD. p 183.

Goodman WK, Price LH, Rasmussen SA, Mazure C, Delgado P, Heninger GR et al (1989b). The Yale-Brown Obsessive Compulsive Scale. II. Validity. Arch Gen Psychiatry 46: 1012-1016.

Goodman WK, Price LH, Rasmussen SA, Mazure C, Fleischmann RL, Hill CL et al (1989c). The Yale-Brown Obsessive Compulsive Scale. I. Development, use, and reliability. Arch Gen Psychiatry 46: 1006-1011.

Greenberg BD, Benjamin J, Martin JD, Keuler D, Huang SJ, Altemus $\mathrm{M}$ et al (1998). Delayed obsessive-compulsive disorder symptom exacerbation after a single dose of a serotonin antagonist in fluoxetine-treated but not untreated patients. Psychopharmacology (Berl) 140: 434-444.

Hamilton M (1960). A rating scale for depression. J Neurol Neurosurg Psychiatry 23: 56-62.

Ibrahim L, Diaz Granados N, Jolkovsky L, Brutsche N, Luckenbaugh DA, Herring WJ et al (2012). A Randomized, placebocontrolled, crossover pilot trial of the oral selective NR2B antagonist MK-0657 in patients with treatment-resistant major depressive disorder. J Clin Psychopharmacol 32: 551-557.

Johnson JW, Kotermanski SE (2006). Mechanism of action of memantine. Curr Opin Pharmacol 6: 61-67.

Koran LM, Hanna GL, Hollander E, Nestadt G, Simpson HB (2007). Practice guideline for the treatment of patients with obsessivecompulsive disorder. Am J Psychiatry 164(7 Suppl): 5-53.

Koran LM, Leventhal JL, Fireman B, Jacobson A (2000). Pharmacotherapy of obsessive-compulsive disorder in a health maintenance organization. Am J Health-System Pharmacy 57: 1972-1978.

Lafleur DL, Pittenger C, Kelmendi B, Gardner T, Wasylink S, Malison RT et al (2006). N-acetylcysteine augmentation in serotonin reuptake inhibitor refractory obsessive-compulsive disorder. Psychopharmacology (Berl) 184: 254-256.

Lehman AF, Lieberman JA, Dixon LB, McGlashan TH, Miller AL, Perkins DO et al (2004). Practice guideline for the treatment of patients with schizophrenia, second edition. Am J Psychiatry 161(2 Suppl): 1-56.

Li N, Lee B, Liu RJ, Banasr M, Dwyer JM, Iwata M et al (2010). mTOR-dependent synapse formation underlies the rapid antidepressant effects of NMDA antagonists. Science 329: 959-964.

McGrath MJ, Campbell KM, Parks CR, Burton FH (2000). Glutamatergic drugs exacerbate symptomatic behavior in a transgenic model of comorbid Tourette's syndrome and obsessive-compulsive disorder. Brain Res 877: 23-30. 
Moghaddam B, Adams B, Verma A, Daly D (1997). Activation of glutamatergic neurotransmission by ketamine: a novel step in the pathway from NMDA receptor blockade to dopaminergic and cognitive disruptions associated with the prefrontal cortex. J Neurosci 17: 2921-2927.

Monteggia LM, Gideons E, Kavalali ET (2012). The role of eukaryotic elongation factor 2 kinase in rapid antidepressant action of ketamine. Biol Psychiatry 73: 1199-1203.

Murphy DL, Mueller EA, Hill JL, Tolliver TJ, Jacobsen FM (1989). Comparative anxiogenic, neuroendocrine, and other physiologic effects of $\mathrm{m}$-chlorophenylpiperazine given intravenously or orally to healthy volunteers. Psychopharmacology (Berl) 98: 275-282.

Murrough JW, Perez AM, Pillemer S, Stern J, Parides MK, Aan Het Rot $\mathrm{M}$ et al (2012). Rapid and longer-term antidepressant effects of repeated ketamine infusions in treatment-resistant major depression. Biol Psychiatry (in press).

Overall JE, Gorham DR (1962). The Brief Psychiatric Rating Scale. Psychol Rep 10: 799-812.

Papolos DF, Teicher MH, Faedda GL, Murphy P, Mattis S (2012). Clinical experience using intranasal ketamine in the treatment of pediatric bipolar disorder/fear of harm phenotype. J Affect Disord 147: 431-436.

Pinto A, Greenberg BD, Grados MA, Bienvenu OJ, Samuels JF, Murphy DL et al (2008). Further development of YBOCS dimensions in the OCD Collaborative Genetics study: symptoms vs categories. Psychiatry Res 160: 83-93.

Pittenger C, Bloch MH, Williams K (2011). Glutamate abnormalities in obsessive compulsive disorder: neurobiology, pathophysiology, and treatment. Pharmacol Ther 132: 314-332.

Rodriguez CI, Bender J Jr., Marcus SM, Snape M, Rynn M, Simpson HB (2010). Minocycline augmentation of pharmacotherapy in obsessive-compulsive disorder: an open-label trial. J Clin Psychiatry 71: 1247-1249.

Rodriguez CI, Kegeles LS, Flood P, Simpson HB (2011). Rapid resolution of obsessions after an infusion of intravenous ketamine in a patient with treatment-resistant obsessivecompulsive disorder. J Clin Psychiatry 72: 567-569.

Rosenberg DR, MacMaster FP, Keshavan MS, Fitzgerald KD, Stewart CM, Moore GJ (2000). Decrease in caudate glutamatergic concentrations in pediatric obsessive-compulsive disorder patients taking paroxetine. J Am Acad Child Adolesc Psychiatry 39: 1096-1103.

Rosenberg DR, Mirza Y, Russell A, Tang J, Smith JM, Banerjee SP et al (2004). Reduced anterior cingulate glutamatergic concentrations in childhood OCD and major depression versus healthy controls. J Am Acad Child Adolesc Psychiatry 43: 1146-1153.

Rowland LM, Bustillo JR, Mullins PG, Jung RE, Lenroot R, Landgraf $\mathrm{E}$ et al (2005). Effects of ketamine on anterior cingulate glutamate metabolism in healthy humans: a 4 -T proton MRS study. Am J Psychiatry 162: 394-396.

Schooler C, Revell AJ, Timpano KR, Wheaton M, Murphy DL (2008). Predicting genetic loading from symptom patterns in obsessive- compulsive disorder: a latent variable analysis. Depress Anxiety 25: 680-688.

Shugart YY, Wang Y, Samuels JF, Grados MA, Greenberg BD, Knowles JA et al (2009). A family-based association study of the glutamate transporter gene SLC1A1 in obsessive-compulsive disorder in 378 families. Am J Med Genet B Neuropsychiatr Genet 150B: $886-892$.

Stewart SE, Fagerness JA, Platko J, Smoller JW, Scharf JM, Illmann $C$ et al (2007). Association of the SLC1A1 glutamate transporter gene and obsessive-compulsive disorder. Am J Med Genet B Neuropsychiatr Genet 144B: 1027-1033.

Stewart SE, Jenike EA, Hezel DM, Stack DE, Dodman NH, Shuster L et al (2010). A single-blinded case-control study of memantine in severe obsessive-compulsive disorder. J Clin Psychopharmacol 30: 34-39.

Stone JM, Dietrich C, Edden R, Mehta MA, De Simoni S, Reed LJ et al (2012). Ketamine effects on brain GABA and glutamate levels with 1H-MRS: relationship to ketamine-induced psychopathology. Mol Psychiatry 17: 664-665.

Taylor MJ, Tiangga ER, Mhuircheartaigh RN, Cowen PJ (2012). Lack of effect of ketamine on cortical glutamate and glutamine in healthy volunteers: a proton magnetic resonance spectroscopy study. J Psychopharmacol 26: 733-737.

Tolin DF, Abramowitz JS, Diefenbach GJ (2005). Defining response in clinical trials for obsessive-compulsive disorder: a signal detection analysis of the Yale-Brown obsessive compulsive scale. J Clin Psychiatry 66: 1549-1557.

Valentine GW, Mason GF, Gomez R, Fasula M, Watzl J, Pittman B et al (2011). The antidepressant effect of ketamine is not associated with changes in occipital amino acid neurotransmitter content as measured by [(1)H]-MRS. Psychiatry Res 191: 122-127.

Wang Y, Adamczyk A, Shugart YY, Samuels JF, Grados MA, Greenberg BD et al (2009). A screen of SLC1A1 for OCD-related alleles. Am J Med Genet B Neuropsychiatr Genet 153B: 675-679.

Welch JM, Lu J, Rodriguiz RM, Trotta NC, Peca J, Ding JD et al (2007). Cortico-striatal synaptic defects and OCD-like behaviours in Sapap3-mutant mice. Nature 448: 894-900.

Young RC, Biggs JT, Ziegler VE, Meyer DA (1978). Young Mania Rating Scale. Br J Psychiatry 133: 429.

Zarate CA Jr., Brutsche NE, Ibrahim L, Franco-Chaves J, Diazgranados N, Cravchik A et al (2012a). Replication of ketamine's antidepressant efficacy in bipolar depression: a randomized controlled add-on trial. Biol Psychiatry 71: 939-946.

Zarate CA Jr., Mathews D, Ibrahim L, Chaves JF, Marquardt C, Ukoh I et al (2012b). A randomized trial of a low-trapping nonselective $N$-methyl-D-aspartate channel blocker in major depression. Biol Psychiatry (in press).

Zarate CA Jr., Singh JB, Carlson PJ, Brutsche NE, Ameli R, Luckenbaugh DA et al (2006). A randomized trial of an $\mathrm{N}$-methyl-D-aspartate antagonist in treatment-resistant major depression. Arch Gen Psychiatry 63: 856-864. 